ISSN 1420-3049

www.mdpi.org/molecules

Article

\title{
Amifostine Protection Against Mitomycin-induced Chromosomal Breakage in Fanconi Anaemia Lymphocytes
}

\author{
Ricardo M. Camelo ${ }^{1}$, Fernanda S. G. Kehdy ${ }^{3}$, Carlos E. Salas ${ }^{2, *}$ and Miriam T. P. Lopes ${ }^{1}$
}

1 Department of Pharmacology, Instituto de Ciências Biológicas, Universidade Federal de Minas Gerais, Belo Horizonte, CEP 31270-901, Brazil

2 Departamento Bioquímica e Imunologia, Instituto de Ciências Biológicas, Universidade Federal Minas Gerais, Antônio Carlos 6627, Belo Horizonte, MG 31270-901, Brazil

3 Department of General Biology, Instituto de Ciências Biológicas, Universidade Federal de Minas Gerais, Belo Horizonte, CEP 31270-901, Brazil

\footnotetext{
* Author to whom correspondence should be addressed. E-mail: cesbufmg@icb.ufmg.br; Phone/Fax: +55-31-3409-2646.
}

Received: 17 June 2008; in revised form: 13 August 2008 / Accepted: 14 August 2008 / Published: 21 August 2008

\begin{abstract}
Fanconi anaemia (FA) is a rare genetic chromosomal instability syndrome caused by impairment of DNA repair and reactive oxygen species (ROS) imbalance. This disease is also related to bone marrow failure and cancer. Treatment of these complications with radiation and alkylating agents may enhance chromosomal breakage. We have evaluated the effect of amifostine (AMF) on basal and mitomycin C (MMC)-induced chromosomal breakage in FA blood cells using the micronucleus assay. The basal micronuclei count was higher among FA patients than healthy subjects. Pre-treatment with AMF significantly inhibited micronucleation induced by MMC in healthy subjects $(23.4 \pm$ $4.0-\mathrm{MMC}$ vs $12.3 \pm 2.9-\mathrm{AMF} \rightarrow \mathrm{MMC}) \mathrm{MN} / 1000 \mathrm{CB}, \mathrm{p}<0.01$, one way ANOVA) as well as in FA patients $(80.0 \pm 5.8-\mathrm{MMC}$ vs $40.1 \pm 5.8-\mathrm{AMF} \rightarrow \mathrm{MMC}) \mathrm{MN} / 1000 \mathrm{CB}, \mathrm{p}$ $<0.01$, ANOVA). Release of ROS by peripheral blood mononuclear cells treated with $\mathrm{AMF} \rightarrow \mathrm{MMC}$ and measured by chemoluminometry showed that AMF-protection was statistically higher among FA patients than in healthy individuals. Based on these results we suggest that AMF prevents chromosomal breakage induced by MMC, probably by its antioxidant effect.
\end{abstract}


Keywords: Fanconi anaemia, amifostine, chromosomal breakage, reactive oxygen species

\section{Introduction}

Fanconi anaemia (FA) is a rare recessive inherited syndrome characterised by chromosomal instability, cellular hypersensitivity to DNA cross linking agents, progressive pancytopenia, congenital malformations and increased predisposition to cancers [1]. The exact pathogenesis has not been elucidated until now, but more than ten altered DNA-repair proteins in the FA/BRCA pathway (the route responsible for maintaining the integrity of the human genome) have been described [2, 3].

Androgen therapy can improve the outcome [4], but side effects (e.g. hepatocarcinoma) and tolerance problems arise [5], thus, bone marrow transplantation has become the only well-established treatment for the pancytopenia associated with FA [4]. Ever since low-dose radiotherapy and alkylating treatments were introduced [6], the survival rate has increased significantly and life expectancy reached 20-30 years [7]. However, in these individuals a high risk of developing solid cancers still persists [8].

The imbalance between production of reactive oxygen species (ROS) and their detoxification was suggested to be a causing factor [9], as addition of superoxide dismutase or catalase to FA cultured cells reduced the frequency of chromosomal aberrations. Later, Joenje et al. found that chromosomal breakage in FA cells augmented with increasing oxygen tension, thus, it was proposed that the primary defect results from a failure to tolerate oxidative stress [10]. On the other hand, antioxidants should help to counter the deleterious effects induced by oxidative stress. Such is the case for mytomicin C (MMC) associated clastogenicity which depends on oxygen levels [11], as this damage decreases upon addition of low-molecular-weight antioxidants [12], or overexpression of thioredoxin [13].

Amifostine (AMF, WR-2721), a phosphorylated aminothiol, is an antioxidant clinically prescribed to prevent the neutropenia-associated events in patients receiving alkylating agents [14]. In experimental animals, Yuhas and Storer showed that treatment with AMF effectively protects normal tissue from the toxicity of therapeutic radiation, without protecting tumours [15]. Once dephosphorylated by the membrane-bound alkaline phosphatase (ALP), AMF is activated to a free thiol form (WR-1065), which is preferentially up taken by normal cells, since ALP is more active and efficiently expressed in normal rather than neoplastic tissue [16, 17]. Nagy et al. subsequently showed that AMF provides protection against the mutagenic effects of cisplatin, evaluated by the mutation rate of HPRT in V79 Chinese hamster cells [18].

The aim of this study was to evaluate the cytoprotective effect of AMF on spontaneous or MMCinduced chromosomal damage in peripheral lymphocytes from FA patients. To identify a possible mechanism of action for AMF, ROS emission was studied following AMF exposure. 


\section{Results and Discussion}

We examined blood from 7 FA patients and 6 healthy volunteers, grouped in 5 for each assay (Table 1). The diagnosis of FA patients was based on clinical criteria and positive chromosomal breakage test. Half of FA donors received oxymetholone for at least one period during their treatment. To verify the ALP activity in PBMC, the NBT-BCIP metabolization method was employed.

Table 1. Profile of subjects participating in the study.

\begin{tabular}{|c|c|c|c|c|c|c|c|c|}
\hline \multicolumn{3}{|c|}{ Control probands } & \multicolumn{6}{|c|}{ FA probands } \\
\hline \multirow{2}{*}{ Code } & \multirow{2}{*}{ Age } & \multirow{2}{*}{ Sex } & \multirow{2}{*}{ Code } & \multirow{2}{*}{ Age } & \multirow{2}{*}{ Sex } & \multicolumn{2}{|c|}{ Chromosomal breakage } & \multirow{2}{*}{ OXM } \\
\hline & & & & & & Spontaneous & MMC & \\
\hline FMG & 20 & $\mathrm{M}$ & ACS & 8 & M & 0.90 & 10.32 & - \\
\hline FSC & 18 & $\mathrm{~F}$ & CCF & 12 & $\mathrm{~F}$ & 0.50 & 1.16 & + \\
\hline LES & 15 & M & CBS & 24 & $\mathrm{~F}$ & 2.16 & 12.91 & - \\
\hline LGBC & 14 & $\mathrm{M}$ & EMM & 17 & M & 1.20 & 6.12 & + \\
\hline SSS & 25 & $\mathrm{~F}$ & RGS & 8 & $\mathrm{~F}$ & 0.84 & 7.00 & - \\
\hline \multirow[t]{2}{*}{ TMBC } & 17 & $\mathrm{~F}$ & VBM & 7 & $\mathrm{M}$ & 0.80 & 4.80 & - \\
\hline & & & VALA & 13 & $\mathrm{M}$ & 0.92 & 2.56 & + \\
\hline
\end{tabular}

FA, Fanconi anaemia; M, male; F, female; OXM, oxymetholone + or - indicates prior treatment; MMC, mitomycin C. A spontaneous chromosomal break index $\geq 0.5$ or induced break $\geq 1$ was required for FA subjects. Normal subjects had chromosomal break index $\leq 0.1$ (not shown)

ALP activities from healthy and FA PBMC did not show significant differences $(1.1 \pm 0.2$ vs. $1.6 \pm$ 0.4, respectively, data not shown). The effect of AMF on spontaneous and MMC-induced chromosomal breakage was studied in lymphocytes from FA or healthy subjects, by the cytokinesisblock micronucleus test. Mean frequencies of MN are shown in Figure 1A. Basal levels of MN were higher among FA subjects than control volunteers ( $p<0.05$, unpaired Student's $t$ test). Isolated AMF treatment did not significantly change the basal frequencies in either group, but, isolated MMC treatment significantly enhanced the MN frequencies from both groups ( $p<0.05$, one way ANOVA). The enhancement in MN frequency induced by MMC was significantly higher among healthy volunteers than FA subjects (Figure 1B, $p<0.05$, unpaired Student's $t$ test). However, cells pre-treated with AMF for 30 min prevented the increase in MN frequency induced by MMC (Figure 1A), and this protection was similar for both groups (Figure 1B). 
Figure 1. Protective effect of amifostine on mitomycin-induced micronucleation in FA peripheral blood lymphocytes.

$\mathbf{A}$

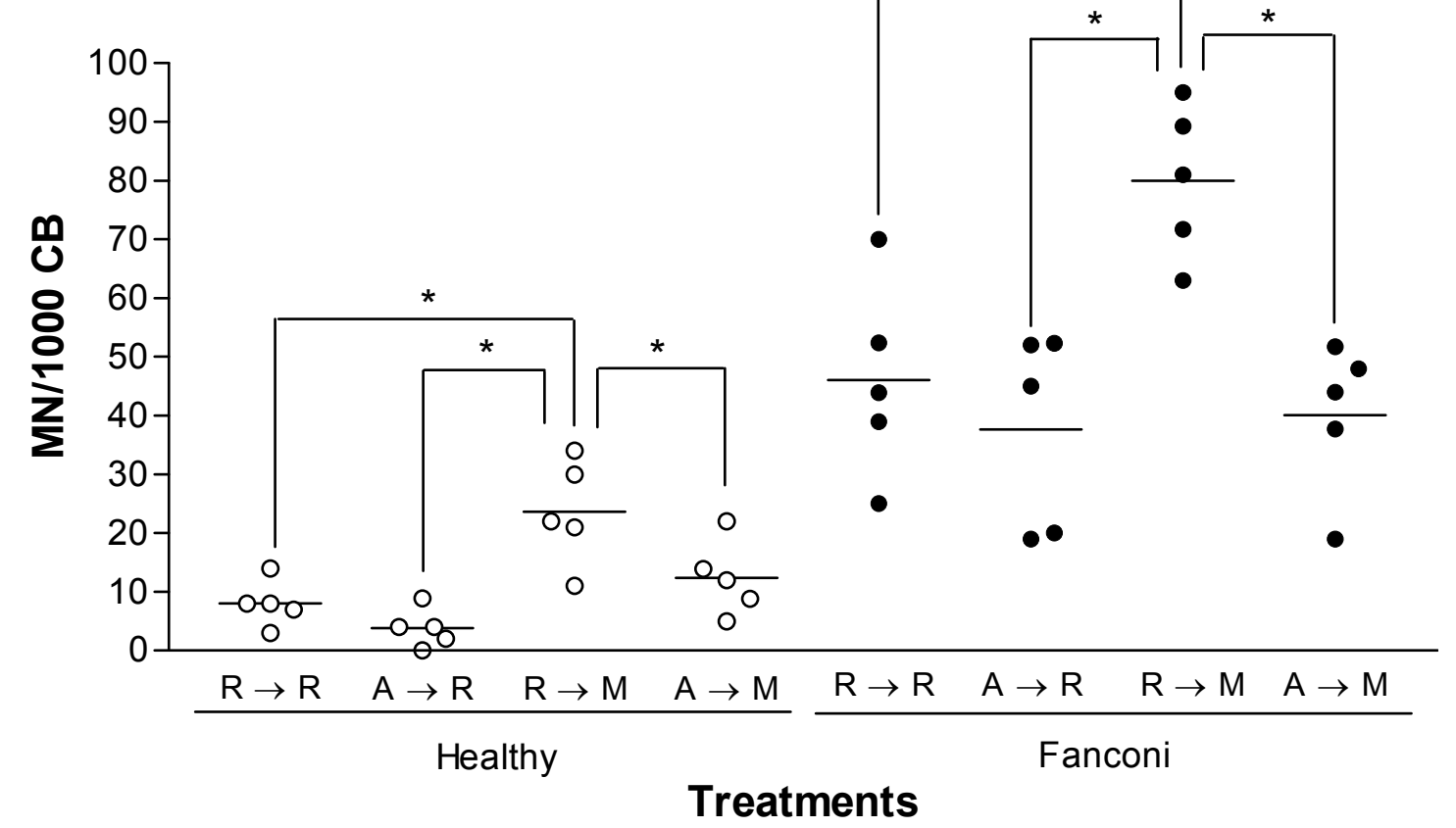

B

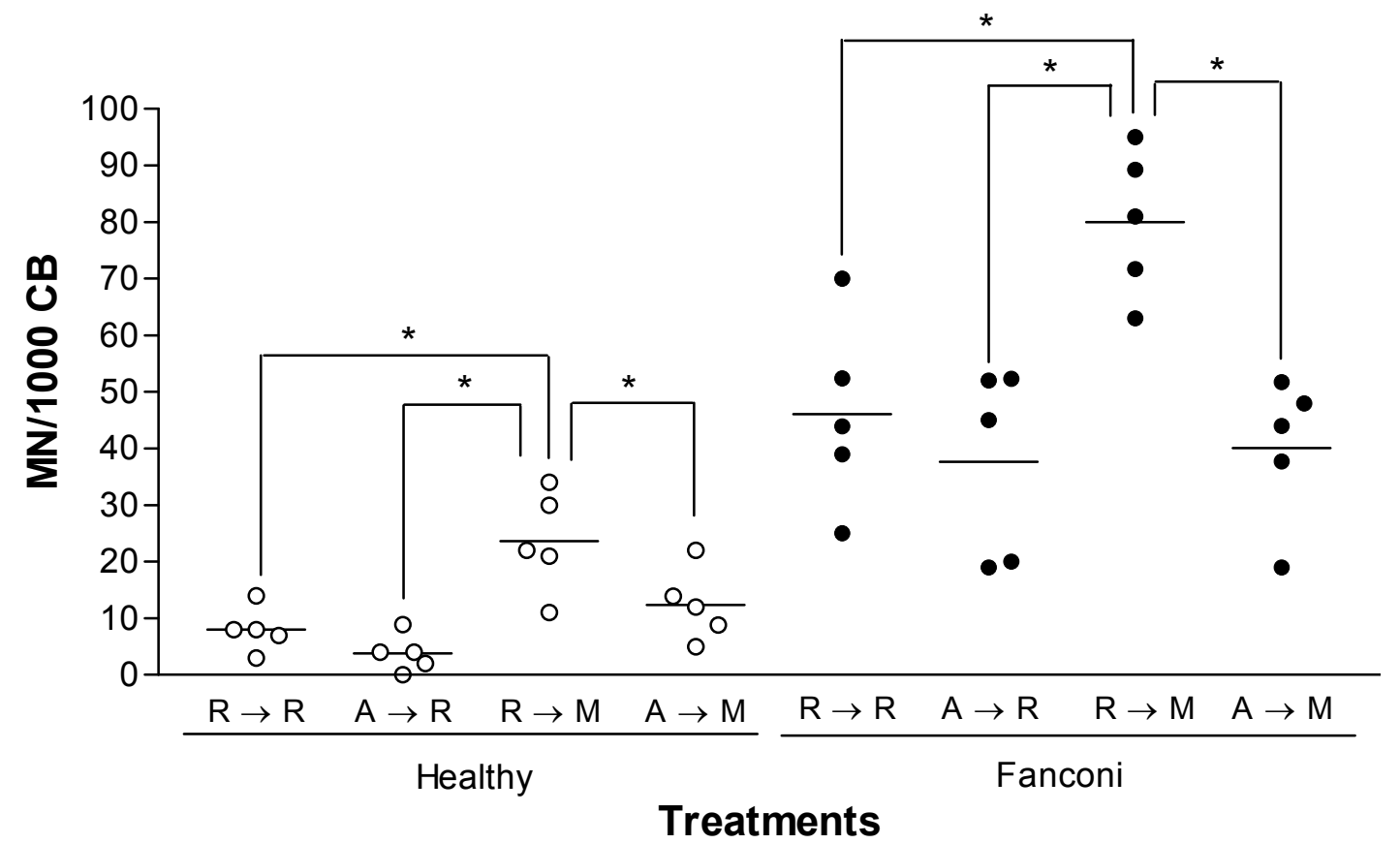

Cells were exposed to $1.2 \mathrm{mg} / \mathrm{mL}$ amifostine (A) or RPMI 1640 vehicle (R) for $30 \mathrm{~min}$ and then to 150 $\mathrm{ng} / \mathrm{mL}$ mitomycin (M) or vehicle for $60 \mathrm{~min}$. $\mathbf{R} \rightarrow \mathbf{R}$, RPMI 1640 followed by RPMI 1640; A $\rightarrow \mathbf{R}$, amifostine followed by RPMI 1640; R $\rightarrow$ M, RPMI 1640 followed by mitomycin; $\mathbf{A} \rightarrow \mathbf{M}$, amifostine followed by mitomycin. Cytochalasin B was added to drug-free medium for $48 \mathrm{~h}$. Binucleated cells (BC) were analysed according to the micronucleus test. Figure $1 \mathrm{~A}$ represents the absolute frequency of micronucleation and Figure $1 \mathrm{~B}$ refers to the relative protection by amifostine. One way ANOVA test (Figure 1A) or unpaired Student's $t$ test (Figure 1B), $p<0.05\left(^{*}\right), \mathrm{n}=5$ individuals per treatment. 
Approximately one mitotic event occurred during the experimental period $(1.57 \pm 0.05$ nuclei/cell, for the control group and $1.66 \pm 0.04$ nuclei/cell in FA probands; Figure 2). Exposure to AMF, followed or not by MMC, prolonged the doubling time in both groups, while MMC alone selectively retarded the cell cycle in affected subjects $(p<0.05$, one way ANOVA). No differences in cell viability due to apoptosis or necrosis between treatments influenced cell cycle progression (data not shown).

Figure 2. The nuclear index of lymphocytes from healthy and Fanconi anaemia individuals.

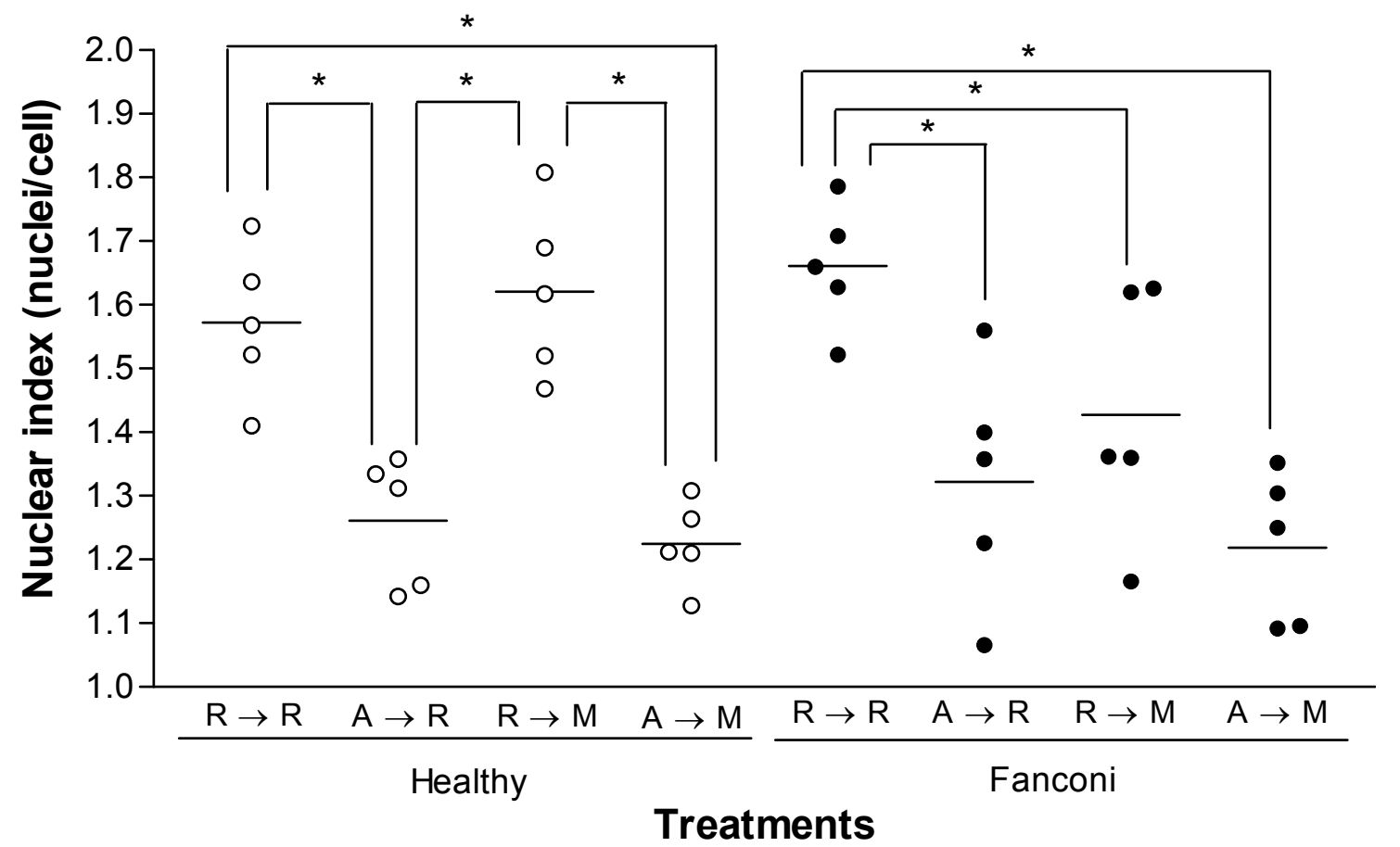

Cells were exposed to $1.2 \mathrm{mg} / \mathrm{mL}$ amifostine (A) or RPMI 1640 vehicle (R) for $30 \mathrm{~min}$ and then to 150 $\mathrm{ng} / \mathrm{mL}$ mitomycin $(\mathrm{M})$ or vehicle for $60 \mathrm{~min}$. $\mathbf{R} \rightarrow \mathbf{R}$, RPMI 1640 followed by RPMI 1640; $\rightarrow \mathbf{R}$, amifostine followed by RPMI 1640; R $\rightarrow \mathbf{M}$, RPMI 1640 followed by mitomycin; $\mathbf{A} \rightarrow \mathbf{M}$, amifostine followed by mitomycin. Cytochalasin B was added in drug-free medium for $48 \mathrm{~h}$. The number of main nuclei per cell was recorded in 500 viable lymphocytes. One way ANOVA test, $p<0.05\left(^{*}\right), \mathrm{n}=5$ individuals per treatment.

In order to explain the AMF-protection against MMC-induced micronucleation, ROS emission was measured in PBMC from healthy and FA volunteers (Figure 3). AMF significantly reduced ROS emission in both control and FA PBMC ( $p<0.05$, one way ANOVA). Treatment with MMC did not affect the relative energy emission from either group, but, treatment with AMF inhibited ROS release from control and FA PBMC, both, during isolated exposure to AMF or in conjunction with MMC (Figure 3, $p<0.05$, one way ANOVA). Protection was significantly higher in PBMC from FA volunteers; $76.3 \pm 4.9 \%$ vs $44.4 \pm 10.9 \%$ for healthy probands, $p<0.05$, Student's $t$ test). 
Figure 3. Amifostine effect on the emission of reactive oxygen species (ROS) by peripheral blood mononuclear cells in healthy and Fanconi anemia subjects.

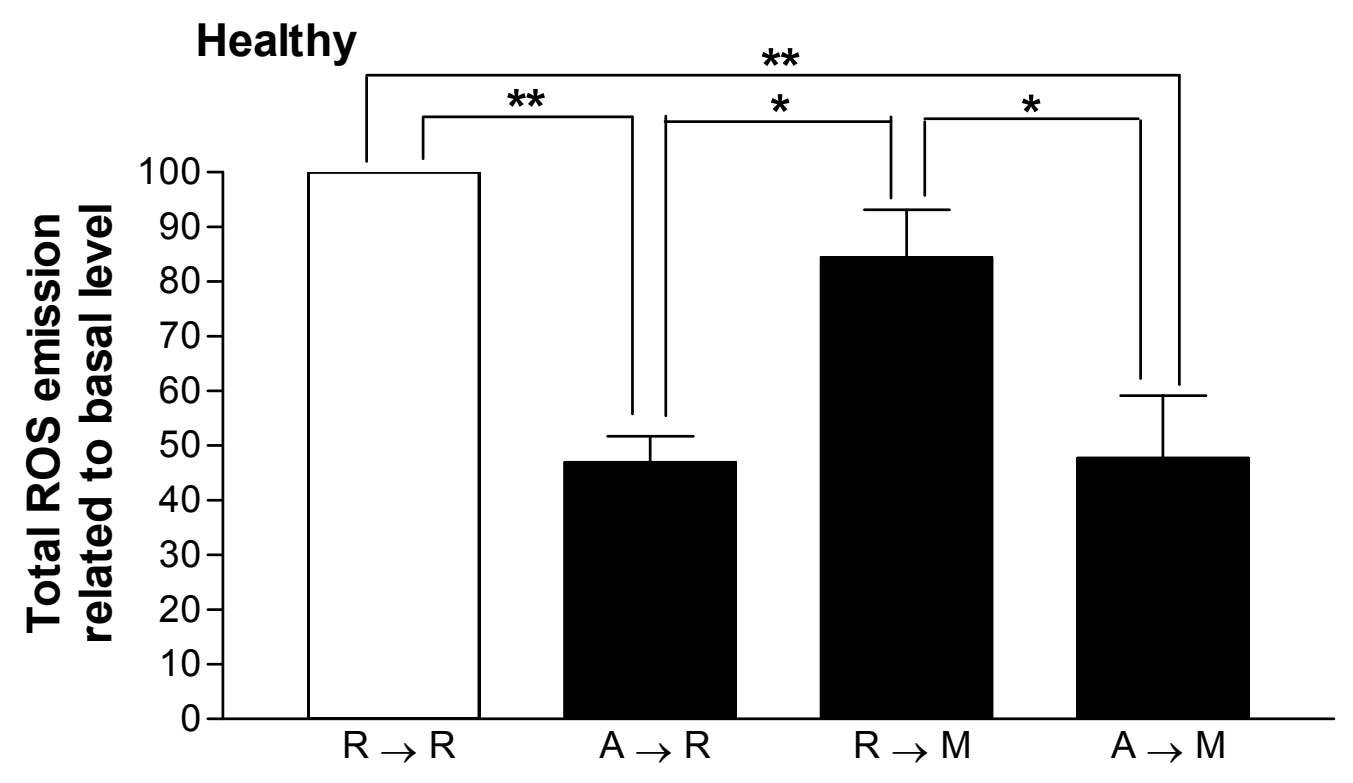

\section{Treatments}

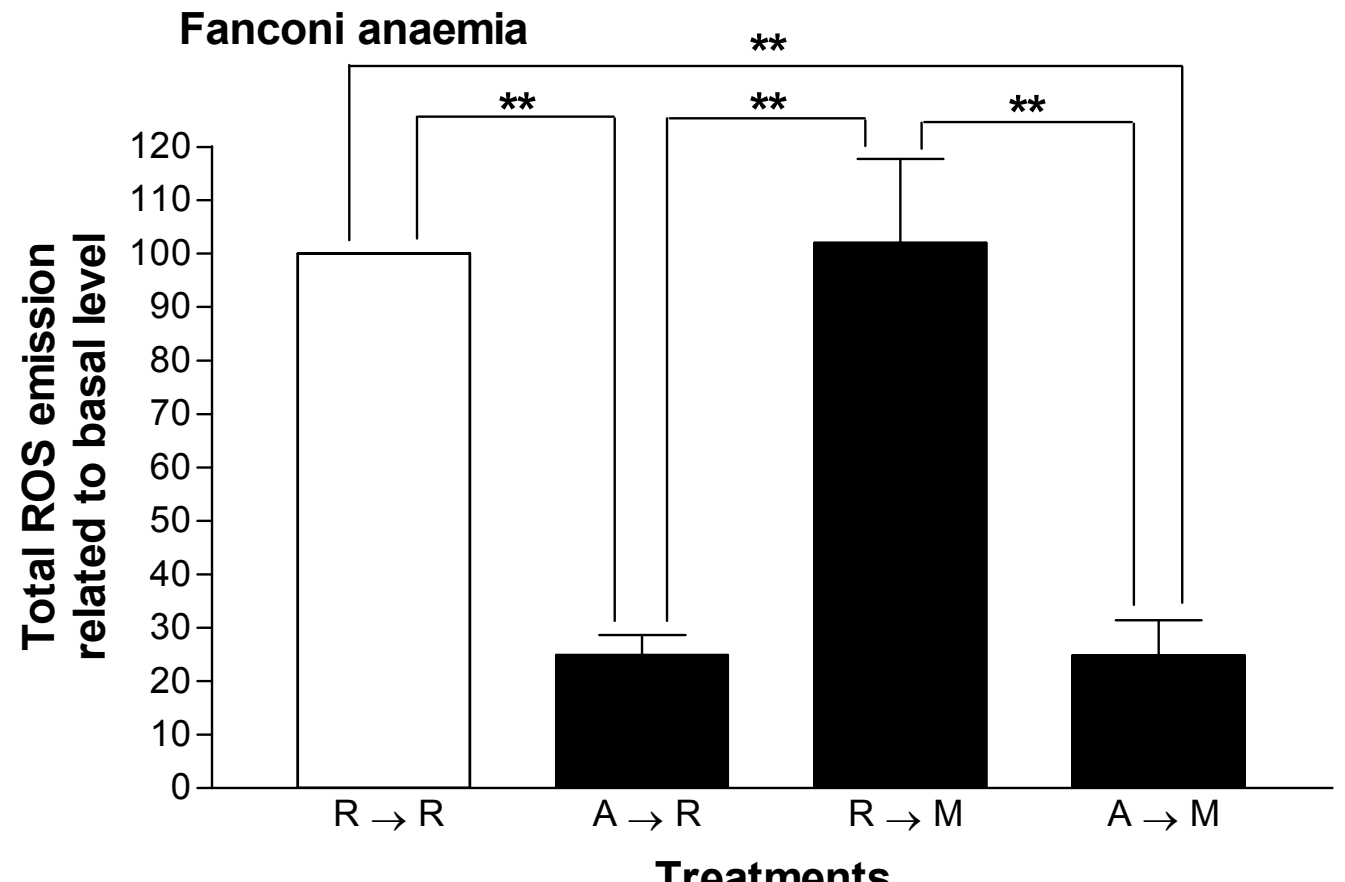

Cells were exposed to $1.2 \mathrm{mg} / \mathrm{mL}$ amifostine (A) or RPMI 1640 vehicle (R) for $30 \mathrm{~min}$ and then to 150 $\mathrm{ng} / \mathrm{mL}$ mitomycin $(\mathrm{M})$ or vehicle for $220 \mathrm{~min}$. $\mathbf{R} \rightarrow \mathbf{R}$, RPMI 1640 followed by RPMI 1640; $\mathbf{A} \rightarrow \mathbf{R}$, amifostine followed by RPMI 1640; R $\rightarrow \mathbf{M}$, RPMI 1640 followed by mitomycin; $\mathbf{A} \rightarrow \mathbf{M}$, amifostine followed by mitomycin. ROS emission was measured by the luminol chemiluminescence method and total emission by PBMC exposed to vehicle only (basal) was considered 100\%. One way ANOVA, $p<0.01(*), p$ $<0.001(* *), \mathrm{n}=5$ individuals per treatment.

The intrinsic enhanced chromosomal sensitivity to radiation and alkylating agents in FA constitutes an important risk factor for mutagenesis and/or carcinogenesis during the conditioning regimen for 
bone marrow transplantation and during conventional treatment of cancers afflicting these individuals. Based on this notion, we tested the protective effect of AMF against chromosomal breakage induced by MMC in peripheral blood lymphocytes of FA patients.

The micronucleus test is employed as a tool for measuring mutagenesis in several cell types, including FA cells [13, 20, 21]. We used this test to evaluate genoprotection, as an alternative costeffective method, previously used for such a purpose [19]. In agreement with studies in normal lymphocytes [19], we verified a direct relation between spontaneous micronucleation in FA lymphocytes and clastogenicity assessed by the cytogenetic assay used as one of the diagnosis tests for this condition $\left(p<0.05, r^{2}=0.94\right.$, data not shown).

AMF significantly prevented MMC-induced chromosomal breakage in peripheral blood lymphocytes from both, healthy subjects and FA patients, but did not reduce spontaneous FA micronucleation at the basal level (Figure 1). Other researchers showed that AMF was unable to prevent spontaneous micronucleation of normal lymphocytes [22], but inhibited micronucleation induced by alkylating agents [23, 24]. Our observation agrees with data from other groups suggesting that AMF significantly reduces the carcinogenic, mutagenic and clastogenic effects of cancer therapy [22, 25-27]. Moreover, extensive in vitro and in vivo evaluations of AMF against radiation- and chemotherapy-induced mutations at the HGPRT locus in V79 cells and radiation-induced carcinogenesis confirm the genoprotective effects of the aminothiol [25, 26, 28].

The basis for selective cytoprotection of normal tissue by AMF is explained by its unique systemic and tissue-distribution pharmacokinetics [29]. A high concentration of ALP, the AMF activating enzyme, occurs in capillaries of normal tissues [16, 30], while a lower level and activity of ALP are observed in the fragile endothelium of cancer vessels due to the more acidic environment [17]. Consequently, AMF acts preferentially against chemotherapy-induced DNA damage in normal tissues, rather than in cancer cells [31]. These data explain why AMF pretreatment of tumour-bearing animals increases the therapeutic index of anticancer drugs [32]. Our results demonstrate that PBMC from both groups of subjects exhibit similar ALP activity, thus yielding similar AMF concentrations on each group, hence, the protective effect of AMF must be consequence of a different mechanism.

An important mechanism of cytoprotection involves the ability of free thiol groups to act as scavengers for oxygen free radicals, such as those derived from specific drugs or radiation therapy [33]. AMF significantly prevented the release of reactive oxygen species in both control and FA individuals (Figure 2). The ROS emission induced in both groups by AMF was unchanged by the addition of MMC. However, the antioxidative effect by AMF was stronger in FA cells compared to its control (Figure 3, $\mathrm{A} \rightarrow \mathrm{M}$ ). This evidence signals an oxidative imbalance in FA cells exposed to oxidative stress. In line with these data, prior evidence showed that low levels of thioredoxin in FA fibroblasts and consequent lost of sensitivity to $\mathrm{MMC}$, was restored by thioredoxin overexpression [34]. The vulnerability to oxidative stress by FA is explained, as some FANC proteins are linked to redox pathways: i.e., FANCA, FANCC, and FANCG [35-38]. The absence of ROS changes in $\mathrm{R} \rightarrow \mathrm{M}$ compared to $\mathrm{R} \rightarrow \mathrm{R}$ in normal and Fanconi probands (Figure 3 ) is justified by the low MMC dose $(0.5$ $\mu \mathrm{M}$ ) used, as other authors reported that ROS formation at low MMC dose is not significant [11]. In this case the clastogenic effect is associated with formation of $\bullet \mathrm{MMC}$ radical, a species that also reacts with DNA. 
Although the basal nuclear indices were similar in both experimental groups (Figure 2 RPMI $\rightarrow$ RPMI), the longer arrest on the duplication time in FA cells containing MMC could result from impairment in DNA repair, as suggested before [39]. Meanwhile, North et al. suggested a direct genotoxic effect of AMF which could interrupt cell cycle progression, but we could not confirm this effect by the micronucleus test [40]. The delaying effect by AMF is unrelated to cell apoptosis or necrosis, since control assays (morphological Giemsa staining; data not shown) failed to detect significant changes of these phenomena. DNA binding to AMF or its metabolites to protect from ROS attack may interfere in the activity of some enzymes, such as topoisomerases and the interference of some transcription factors, such as NF- $\mathrm{B}, \mathrm{AP}-1$ and $\mathrm{p} 53$ could explain the arrest observed in the present study [41-43]. Interestingly, a recent report shows that AMF improves conditioning of FA bone marrow cells before transplantation [44].

The American Society of Clinical Oncology approved the use of AMF to reduce the neutropeniaassociated events in patients receiving alkylating agents, during chemotherapeutic treatment [14]. In addition, AMF and its disulfide WR-33278 display myelostimulatory properties on normal stem cells, likely by its structural similarity with endogenous polyamines, usually related to cell proliferation and differentiation [45].

Since Nordenson described the correction of chromosomal abnormalities in FA cells exposed to superoxide dismutase and catalase in vitro, many studies reported the genoprotective effect by enzyme supplementation or antioxidants [9, 12, 13]. However, a single report describes a reduction of chromosomal instability in a FA patient treated with rutin, leading to suggestion of a diet rich in antioxidants for these individuals [46, 47].

The protective effects of AMF and/or its metabolites on DNA alkylation or free radical induced DNA damage not only have implications on acute cytotoxic manifestations from therapy, but also against potential genotoxic effects of oncostatic therapies resulting in secondary malignancies [25]. To our knowledge, this is the first study involving AMF as a cytoprotector for FA. We have shown that AMF can prevent MMC-induced chromosomal breakage, probably by reducing the pro-oxidative state of mononuclear cells. Future research should investigate the levels of antioxidants in FA cells and the modulation induced by AMF exposition. Clinical trials with AMF should be encouraged before bone marrow conditioning or prior to chemo- or radiotherapies used for cancer treatment.

\section{Experimental}

\section{Subject eligibility}

A total of seven FA patients (Table 1, five randomly chosen for each assay) were selected according to the following diagnostic criteria: (a) clinical manifestations of the disease (haematological abnormalities and/or congenital anomalies typical of FA) and (b) cytogenetic studies (spontaneous chromatid breakage and hypersensitivity to MMC) in phytohaemagglutinin-stimulated lymphocytes. Six normal, healthy- and sex-matched volunteers (Table 1, five randomly chosen for each assay) were recruited as controls. Their spontaneous chromosomal break index was lower than 0.1. General exclusion criteria were: (1) inpatients, (2) prior bone marrow transplantation, (3) previous or current diagnosis of malignancy and (4) tabagism or habitual alcoholism. A sample from every subject was used in each experiment. The study received approval from the Committee on Ethics and Research of 
the Federal University of Minas Gerais, Belo Horizonte, Brazil. Free informed consent was obtained from all subjects.

Sample collection and isolation of peripheral blood mononuclear cells (PBMC)

Peripheral blood samples (3-4 mL in EDTA-vacutainer tubes) were obtained when patients attended a routine physician visit. PBMC from FA patients and control subjects were isolated by Hystopaque ${ }^{\circledR}$ (Sigma) sedimentation and washed twice in phenol red-free RPMI 1640.

\section{Chemicals and culture medium}

Cytochalasin B (Cyt-B; Sigma); phytohaemagglutinin A (PHA; GIBCO); luminol (5-amine-2,3dihydro-1,4-phtalazinedione, Sigma); nitrobluetetrazolium chloride (NBT; Gibco); $p$-toluidine 5bromo-4-chloro-3-indolylphosphate (BCIP; Gibco); amifostine (AMF, Ethyol ${ }^{\circledR}$; Schering-Plough); mitomycin C (MMC, Mytocin ${ }^{\circledR}$; Bristol-Myers) were used in this study.

Lymphocytes were cultivated in RPMI 1640 medium, supplemented with $7.5 \% \mathrm{NaHCO}_{3}(\mathrm{w} / \mathrm{v})$, $20 \%$ foetal bovine serum (v/v) (FBS; Gibco), 2 mmol/L l-glutamine (Gln; Gibco) and antibiotics (100 $\mathrm{U} / \mathrm{mL}$ penicillin, $100 \mu \mathrm{g} / \mathrm{mL}$ streptomycin and $25 \mu \mathrm{g} / \mathrm{mL}$ amphotericine B; Gibco).

\section{Alkaline phosphatase activity}

Erythrocytes were removed from PBMC pellet by rinsing with haemolysis buffer $\left(8.29 \mathrm{~g} / \mathrm{L} \mathrm{NH}_{4} \mathrm{Cl}\right.$, $1.0 \mathrm{~g} / \mathrm{L} \mathrm{KHCO}_{3}, 37.2 \mathrm{mg} / \mathrm{L}$ EDTA, in deionized water, $\mathrm{pH}$ 7.2-7.4). The pellet was then resuspended in ALP buffer (12.1 g/L Tris base - TRIZMA ${ }^{\circ B A S E}$, Sigma -, $5.85 \mathrm{~g} / \mathrm{L} \mathrm{NaCl}, 4.75 \mathrm{~g} / \mathrm{L} \mathrm{MgCl}_{2} .6 \mathrm{H}_{2} \mathrm{O}$, in deionized water, $\mathrm{pH} 9.0)$ at a final density of $5 \times 10^{6}$ cells $/ \mathrm{mL}$.

NBT $(330 \mathrm{ng} / \mathrm{mL})$ and then BCIP $(65 \mathrm{ng} / \mathrm{mL})$ were added and, after $3 \mathrm{~h}$ in the darkness $\left(37^{\circ} \mathrm{C}\right), 3-5$ aliquots $(100-200 \mu \mathrm{L})$ were distributed on a $24-w e l l$ plate and then $10 \%$ SDS-HCl $(\mathrm{v} / \mathrm{v})$ was added and incubated for $18 \mathrm{~h}$ at $37^{\circ} \mathrm{C}$. The colorimetric reaction was spectrophotometrically measured at $\lambda=570$ $\mathrm{nm}$ ) and blanks containing buffer plus NBT and BCIP were subtracted from experimental points.

\section{Micronucleus assay}

The micronucleus (MN) assay was performed according to Fenech et al. (19) with modifications. Cells were distributed into 8 tubes $\left(10^{6}\right.$ cells $/ \mathrm{mL}$ for control probands or the whole PBMC suspension for FA patients) and incubated at $37^{\circ} \mathrm{C}$ and $5 \%(\mathrm{v} / \mathrm{v}) \mathrm{CO}_{2}$-humidified atmosphere, in RPMI 1640 medium (Gibco) containing 20\% (v/v) FBS (Gibco) and antibiotics (Gibco), 2 mmol/L Gln (Gibco) and 4\% (v/v) PHA (Gibco). After $44 \mathrm{~h}$ incubation, medium was changed and cells were exposed to 1.2 $\mathrm{mg} / \mathrm{mL}$ AMF (the highest concentration without toxic effect, according to guidelines from Organization for Economic Co-Operation and Development, 1995, or free medium for $30 \mathrm{~min}$ followed by $150 \mathrm{mg} / \mathrm{mL}$ MMC, or free medium for additional $60 \mathrm{~min}$. Cells were washed twice with free medium and Cyt-B $(6 \mu \mathrm{g} / \mathrm{mL})$ was added for $48 \mathrm{~h}$. Each assay was done in duplicate and pooled before fixation.

Cells were harvested by centrifugation and fixed in 3:1 70\% methanol: acetic acid (v/v) and distributed onto two slides. Cells were stained with 4\% (v/v) Giemsa (Gibco) for 15 min and nuclear 
changes microscopically identified (1000x by immersion) by a trained person who did not know to which proband the slide belongs to.

From 1-4 nuclei were scored in 500 viable lymphocytes and the nuclear index (NI) calculated according to equation (1):

$$
\mathrm{NI}=(\mathrm{MC}+2 \times \mathrm{BC}+3 \times \mathrm{TC}+4 \times \mathrm{QC}) / \text { total viable cells }
$$

where MC, BC, TC and QC represents mono-, bi-, tri- or tetranucleated cells, respectively.

Scoring of MN was performed in BC. A total of 1000 BC with distinct, homogeneously coloured and sized nuclei were scored on each proband, according to the following criteria: (1) rounded body(ies) with a diameter between $1 / 16$ and $1 / 3$ of the main nuclei; (2) non-refractivity; (3) staining not darker than the main nuclei; (4) the main nuclei can be contacting but not overlapping.

\section{Chemiluminescence analysis}

PBMC were washed twice in phenol red-free RPMI 1640 and adjusted to a final concentration of up to $5 \times 10^{6}$ cells $/ \mathrm{mL}$. Each condition was assayed in duplicate in a 96-well tarnished plate to which luminol was added to a final concentration of $0.01 \mathrm{~mol} / \mathrm{L}$ at time $\mathrm{t}=0 \mathrm{~min}$. At this time, cells were exposed for $30 \mathrm{~min}$ to $1.2 \mathrm{mg} / \mathrm{mL}$ AMF or medium (vehicle) and then to $150 \mathrm{ng} / \mathrm{mL} \mathrm{MMC} \mathrm{or} \mathrm{vehicle}$ for the last $220 \mathrm{~min}$. ROS emission was measured by a chemiluminometer (LumiCount Microplate Luminometer, Packard) in the darkness at $37^{\circ} \mathrm{C}$, shaking the plate for $1 \mathrm{~s}$ before each reading and with the following instrument settings: gain of $32,1100 \mathrm{~V}$ at the photomultiplier tube and $0.5 \mathrm{~s}$ for photon capture. Reading was made with 2-min intervals during the first $30 \mathrm{~min}$ followed by 45 readings at 5 min intervals. The emission produced by a blank containing medium plus luminol was subtracted from experimental values. The total emission (luminosity) was calculated as the area under the curve and plotted as ROS emission $v s$. time. The basal emission obtained by treatment with RPMI $1640 \rightarrow$ RPMI 1640) was assigned $100 \%$ and used as reference.

\section{Statistical analysis}

Differences between the experimental values, means and variances were statistically analysed by PRISM (GraphPad, San Diego, CA) software. Statistical analysis was performed by one way ANOVA followed by unpaired Student's $t$ test or by Newman-Keuls multiple comparison test. A $p$ value $\leq 0.05$ was considered statistically significant.

\section{Acknowledgements}

We would like to thank Dr. Victor Hugo Rodrigues and Dr. Charles A. J. Pádua for the help in acquiring the amifostine, Dr. Renato Nogueira Costa for his support and Dr. Leda Quércia Vieira for the chemiluminometry experiments. We would specially thank Dr. Cybele de Andrade Paes and her staff in the Department of Haematology, Faculty of Medicine, UFMG, for introducing us to their patients. This research was supported by CNPq and Fapemig. 


\section{References}

1. Alter, B. P. Cancer in Fanconi anemia, 1927-2001. Cancer 2003, 97, 425-440.

2. Papadopoulo, D.; Moustacchi, E. L'anémie de Fanconi: gènes et fonction(s) revisités. Med. Sci. 2005, 21, 730-736.

3. Levitus, M.; Joenje, H.; de Winter, J. P. The Fanconi anemia pathway of genomic maintenance. Cell Oncol. 2006, 28, 3-29.

4. Liu, J. M.; Buchwald, M.; Walsh, C. E.; Young, N. S. Fanconi anemia and novel strategies for therapy. Blood 1994, 84, 3995-4007.

5. Velazquez, I.; Alter, B. P. Androgens and liver tumors: Fanconi's anemia and non-Fanconi's conditions. Am. J. Hematol. 2004, 77, 257-267.

6. Gluckman, E.; Devergie, A.; Dutreix, J. Radiosensitivity in Fanconi anaemia: application to the conditioning regimen for bone marrow transplantation. Br. J. Haematol. 1983, 54, 431-440.

7. Zanis-Neto, J.; Flowers, M. E.; Medeiros, C. R.; Bitencourt, M. A.; Bonfim, C. M.; Setúbal, D. C.; Funke, V.; Sanders, J.; Deeg, H. J.; Kiem, H. P.; Martin, P.; Leisenring, W.; Storb, R.; Pasquini, R. Low-dose cyclophosphamide conditioning for haematopoietic cell transplantation from HLA-matched related donors in patients with Fanconi anaemia. Br. J. Haematol. 2005, 130, 99-106.

8. Rosenberg, P. S.; Greene, M. H.; Alter, B. P. Cancer incidence in persons with Fanconi's anemia. Blood 2003, 101, 822-826.

9. Nordenson, I. Effect of superoxide dismutase and catalase on spontaneously occurring chromosome breaks in patients with Fanconi's anemia. Hereditas 1977, 86, 147-150.

10. Joenje, H.; Arwert, F.; Eriksson, A.W.; de Koning, H.; Oostra, A.B. Oxygen-dependence of chromosomal aberrations in Fanconi's anaemia. Nature 1981, 290, 142-143.

11. Korkina, L. G.; Deeva, I. B.; Iaccarino, M.; Oral, R.; Warnau, M.; Pagano, G.; Redox dependent toxicity of diepoxybutane and mitomycin $\mathrm{C}$ in sea urchin embryogenesis. Carcinogenesis $\mathbf{2 0 0 0}$, 21, 213-220.

12. Raj, A. S.; Heddle, J. A. The effect of superoxide dismutase, catalase and L-cysteine on spontaneous and on mitomycin $\mathrm{C}$ induced chromosomal breakage in Fanconi's anemia and normal fibroblasts as measured by the micronucleus method. Mutat. Res. 1980, 78, 59-66.

13. Ruppitsch, W.; Meisslitzer, C.; Hirsch-Kauffmann, M.; Schweiger, M. Overexpression of thioredoxin in Fanconi anemia fibroblasts prevent the cytotoxic and DNA damaging effect of mitomycin C and diepoxybutane. FEBS Lett. 1998, 422, 99-102.

14. Schuchter, L. M.; Hensley, M. L.; Meropol, L. J.; Winer, E. P., American Society of Clinical Oncology, Chemotherapy and Radiotherapy Expert Panel 2002 update of recommendations for the use of chemotherapy and radiotherapy protectants: clinical practice guidelines of the American Society of Clinical Oncology. J. Clin. Oncol. 2002, 20, 2895-2903.

15. Yuhas, J. M.; Storer, J. B. Differential chemoprotection of normal and malignant tissues. J. Natl. Cancer Inst. 1969, 42, 331-335.

16. Calabro-Jones, P. M.; Fahey, R. C.; Smoluk, G. D.; Ward, J. F. Alkaline phosphatase promotes radioprotection and accumulation of WR-1065 in V79-171 cells incubated in medium containing WR-2721. Int. J. Radiat. Biol. 1985, 47, 23-27. 
17. Giatromanolaki, A.; Sivridis, E.; Maltezos, E.; Koukourakis, M. I. Down-regulation of intestinaltype alkaline phosphatase in the tumor vasculature and stroma provides a strong basis for explaining amifostine selectivity. Semin. Oncol. 2002, 29 (Suppl 19), 14-21.

18. Nagy, B.; Dale, P. J.; Grdina, D. J. Protection against cis-diamminedichloroplatinum cytotoxicity and mutagenicity in V79 cells by 2-[(aminopropyl)amino]ethanethiol. Cancer Res. 1986, 46, 1132-1135.

19. Fenech, M.; Holland, N.; Chang, W. P.; Zeiger, E.; Bonassi, S. The Human Micronucleus Project - an international collaborative study on the use of the micronucleus technique for measuring DNA damage in humans. Mutat. Res. 1999, 428, 271-283.

20. Rudd, N. L.; Hoar, D. I.; Greentree, C. L.; Dimnik, L. S.; Hennig, U. G. Micronucleus assay in human fibroblasts: a measure of spontaneous chromosomal instability and mutagen hypersensitivity. Environ. Mol. Mutagen. 1998, 12, 3-13.

21. Ramirez, M. H.; Ruppitsch, W.; Hirsch-Kauffmann, M.; Schweiger, M. Chromosomal instability of fanconi anemia cells is not the consequence of a defective repair activity of the ribosomal protein S3. Biochem. Biophys. Res. Commun. 1999, 264, 518-524.

22. Littlefield, L. G.; Joiner, E. E.; Colyer, S. P.; Sallam, F.; Frome, E. L. Concentration-dependent protection against X-ray-induced chromosome aberrations in human lymphocytes by the aminothiol WR-1065. Radiat. Res. 1993, 133, 88-93.

23. Blasiak, J.; Gloc, E.; Mlynarsky, W.; Drzewoski, J.; Skórski, T. Amifostine differentially modulates DNA damage evoked by idarubicin in normal and leukemic cells. Leuk. Res. 2002, 26, 1093-1096.

24. Buschini, A.; Alessandrini, C.; Martino, A.; Pasini, L.; Rizzoli, V.; Carlo-Stella, C.; Poli, P.; Rossi, C. Bleomycin genotoxicity and amifostine (WR-2721) cell protection in normal leukocytes vs. K562 tumoral cells. Biochem. Pharmacol. 2002, 63, 967-975.

25. Grdina, D. J.; Carnes, B. A.; Grahn, D.; Sigdestad, C. P. Protection against late effects of radiation by S-2-(3-aminopropylamino)-ethylphosphorothioic acid. Cancer Res. 1991, 51, 41254130 .

26. Kataoka, Y.; Basic, I.; Perrin, J.; Grdina, D. J. Antimutagenic effects of radioprotector WR-2721 against fission-spectrum neurons and ${ }^{60} \mathrm{Co}$ gamma rays in mice. Int. J. Radiat. Biol. 1992, 61, 387-392.

27. Grdina, D. J.; Nagy, B.; Hill, C. K.; Wells, R. L.; Peraino, C. The radioprotector WR1065 reduces radiation-induced mutations at the hypoxanthine-guanine phosphoribosyl transferase locus in V79 cells. Carcinogenesis 1985, 6, 929-931.

28. Nagy, B.; Grdina, D. J. Protective effects of 2-[(aminopropyl)amino]ethanethiol against bleomycin and nitrogen mustard-induced mutagenicity in V79 cells. Int. J. Radiat. Oncol. Biol. Phys. 1986, 12, 1475-1478.

29. Shall, L. M.; Glover, D.; Turrisi, A.; Brown, D. Q.; Bonner, H. S.; Norfleet, A. L.; Weiler, C.; Glick, J. H.; Kligerman, M. M. Pharmacokinetics of WR-2721. Pharmacol. Therapeut. 1988, 39, 195-201.

30. Romanul, F. C.; Bannister, R. G. Localized areas of high alkaline phosphatase activity in endothelium of arteries. Nature 1962, 195, 611-612.

31. Mori, T.; Nikaido, O.; Suguhara, T. Dephosphorylation of WR-2721 with mouse tissue 
homogenates. Int. J. Radiat. Oncol. Biol. Phys. 1984, 10, 1529-1531.

32. Valeriote, F.; Tolen, S. Protection and potentiation of nitrogen mustard cytotoxicity by WR2721. Cancer Res. 1982, 42, 4330-4331.

33. Facorro, G.; Sarrasaque, M. M.; Torti, H.; Hager, A.; Avalos, J. S.; Foncuberta, M.; Kusminsky, G. Oxidative study of patients with total body irradiation: effects of amifostine treatment. Bone Marrow Transplant. 2004, 33, 793-798.

34. Pagano, G.; Manini, P.; Bagchi, D. Oxidative stress-related mechanisms are associated with xenobiotics exerting excess toxicity to Fanconi anemia cells. Environ. Health Perspect. 2003, 111, 1699-1703.

35. Mian, I. S.; Moser, M. J. The Fanconi anemia complementation group A protein contains a peroxidase domain. Mol. Genet. Metabol. 1998, 63, 230-234.

36. Kruyt, F. A. E.; Hoshino, T.; Liu, J. M.; Joseph, P.; Jaiswal, A. K.; Youssoufian, H. Abnormal microsomal detoxification implicated in Fanconi anemia group $\mathrm{C}$ by interaction of the FAC protein with NADPH cytochrome P450 reductase. Blood 1998, 92, 3050-3056.

37. Cumming, R. C.; Lightfoot, J.; Beard, K.; Youssoufian, H.; O’Brien, P. J.; Buchwald, M. Fanconi anemia group $\mathrm{C}$ protein prevents apoptosis in hematopoietic cells through redox regulation of GSTP1. Nat. Med. 2001, 7, 814-820.

38. Futaki, M.; Igarashi, T.; Watanabe, S.; Kajigaya, S.; Tatsuguchi, A.; Wang, J.; Liu, J. M. The FANCG Fanconi anemia protein interacts with CYP2E1: possible role in protection against oxidative DNA damage. Carcinogenesis 2002, 23, 67-72.

39. Akkari, Y. M.; Bateman, R. L.; Reifsteck, C. A.; D’Andrea, A. D.; Olson, S. B.; Grompe, M. The 4N cell cycle delay in Fanconi anemia reflects growth arrest in late S phase. Mol. Genet. Metabol. 2001, 74, 403-412.

40. North, S.; El-Ghissassi, F.; Pluquet, O.; Verhaegh, G.; Hainaut, P. The cytoprotective aminothiol WR-1065 activates p21waf-1 and down regulates cell cycle progression through a p53dependent pathway. Oncogene 2000, 19, 1206-1214.

41. Smoluk, G. D.; Fahey, R. C.; Ward, J. F. Equilibrium dialysis studies of the binding of radioprotector compounds to DNA. Radiat. Res. 1986, 107, 194-204.

42. Murley, J. S.; Constantinou, A.; Kamath, N. S.; Grdina, D. J. WR-1065, an active metabolite of the cytoprotector amifostine, affects phosphorylation of topoisomerase II alpha leading to changes in enzyme activity and cell cycle progression in CHO cells. Cell Proliferat. 1997, 30, 283-294.

43. Shen, H.; Chen, Z. J.; Zilfou, J. T.; Hopper, E.; Murphy, M.; Tew, K. D. Binding of the aminothiol WR-1065 to transcription factors influences cellular response to anticancer drugs. Pharmacol. Exp. Ther. 2001, 297, 1067-1073.

44. Cohen-Haguenauer, O.; Peault, B.; Bauche, C.; Daniel, M. T.; Casal, I.; Levy, V.; Dausset, J.; Boiron, M.; Auclair, C.; Gluckman, E.; Marty, M. In vivo repopulation ability of genetically corrected bone marrow cells from Fanconi anemia patients. PNAS 2006, 103, 2340-2345.

45. Jänne, J.; Alhonen, L.; Pietila, M.; Keinanen, T. A. Genetic approaches to the cellular functions of polyamines in mammals. Eur. J. Biochem. 2004, 271, 877-894.

46. Korkina, L. G.; Samochatova, E. V.; Maschan, A. A.; Suslova, T. B.; Cheremisina, Z. P.; Afanasev, I. B. Release of active oxygen radicals by leukocytes of Fanconi anemia patients. $J$. 
Leukocyte Biol. 1992, 52, 357-362.

47. Pagano, G.; Korkina, L. G. Prospects for nutritional interventions in the clinical management of Fanconi anemia. Cancer Cause Control 2000, 11, 881-889.

(C) 2008 by the authors; licensee Molecular Diversity Preservation International, Basel, Switzerland. This article is an open-access article distributed under the terms and conditions of the Creative Commons Attribution license (http://creativecommons.org/licenses/by/3.0/). 